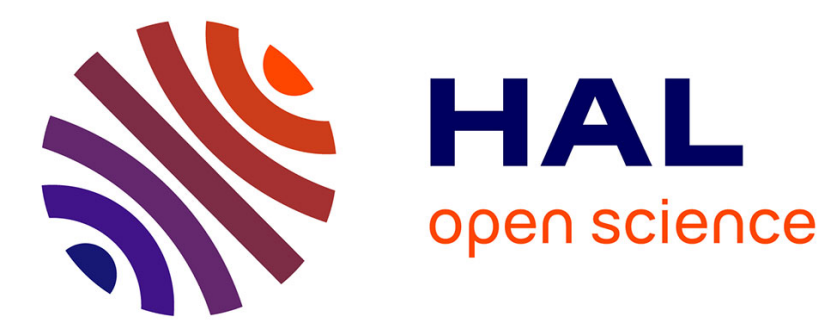

\title{
Microwave spectra and structures of 2-fluoro-4-picoline
}

Shuang Gao, Juan Wang, Meng Li, Isabelle Kleiner, Gang Feng, Qian Gou

\section{To cite this version:}

Shuang Gao, Juan Wang, Meng Li, Isabelle Kleiner, Gang Feng, et al.. Microwave spectra and structures of 2-fluoro-4-picoline. Journal of Molecular Structure, 2020, 1208, pp.127857. 10.1016/j.molstruc.2020.127857 . hal-03410654

\section{HAL Id: hal-03410654 \\ https://hal.science/hal-03410654}

Submitted on 1 Nov 2021

HAL is a multi-disciplinary open access archive for the deposit and dissemination of scientific research documents, whether they are published or not. The documents may come from teaching and research institutions in France or abroad, or from public or private research centers.
L'archive ouverte pluridisciplinaire HAL, est destinée au dépôt et à la diffusion de documents scientifiques de niveau recherche, publiés ou non, émanant des établissements d'enseignement et de recherche français ou étrangers, des laboratoires publics ou privés. 


\title{
Microwave Spectra and Structures of 2-fluoro-4-picoline
}

\author{
Shuang Gao ${ }^{\mathrm{a}}$, Juan Wang ${ }^{\mathrm{a}}$, Meng Li, ${ }^{\mathrm{a}}$ Isabelle Kleiner ${ }^{\mathrm{b}}$, Gang Feng ${ }^{\mathrm{a}}$, Qian Gou ${ }^{\mathrm{a}}$ \\ ${ }^{a}$ Department of Chemistry, School of Chemistry and Chemical Engineering, Chongqing \\ University, Daxuecheng South Rd. 55, 401331, Chongqing, China. \\ ${ }^{b}$ Laboratoire Laboratoire Interuniversitaire des Systèmes Atmosphériques (LISA), UMR CNRS \\ 7583, Université Paris-Est-Créteil (UPEC), Université de Paris, Institut Pierre Simon Laplace \\ (IPSL), 61 av. du Général de Gaulle, 94010 Créteil, Cédex, France
}

\section{AUTHOR INFORMATION}

\section{Corresponding Author}

*Qian Gou, Email: qian.gou@cqu.edu.cn

\section{Highlights}

- The ground state rotational spectra of 2-fluro-4-picoline and its mono-substituted ${ }^{13} \mathrm{C}$ and ${ }^{15} \mathrm{~N}$ isotopologues were assigned.

- The $V_{3}$ barrier to the internal rotation of $\mathrm{CH}_{3}$ has been estimated from the unexpected low values of the inertial defects

- Fluorination effect on the aromatic ring alters the geometry. 


\section{Graphical abstract}

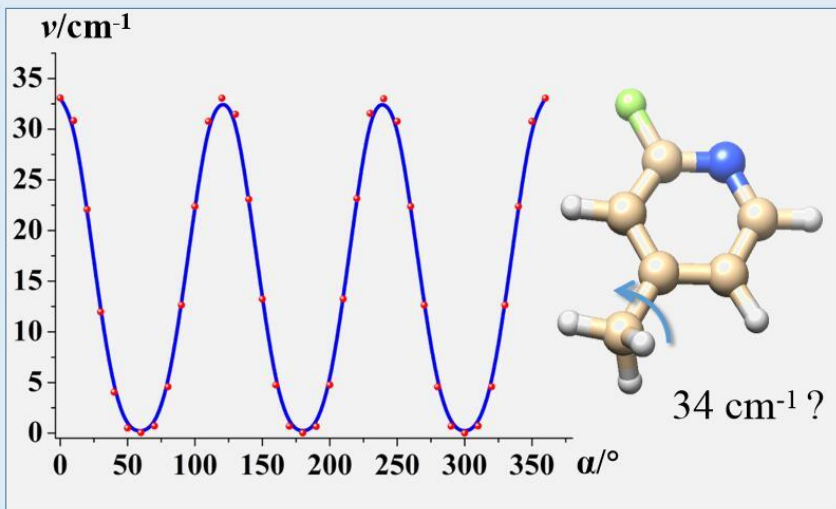




\section{Abstract}

Rotational spectra of the ground state of 2-fluro-4-picoline and its mono-substituted ${ }^{13} \mathrm{C}$ and ${ }^{15} \mathrm{~N}$ isotopologues in nature abundance have been measured and assigned using puled jet Fourier transform microwave spectroscopic technique. The rotational spectrum displays the features of the quadrupole coupling effect of the ${ }^{14} \mathrm{~N}$ nucleus with a near-free internal rotation of $\mathrm{CH}_{3}$ top. The $V_{3}$ barrier $\left(16 \mathrm{~cm}^{-1}\right)$ to the internal rotation of $\mathrm{CH}_{3}$ has been estimated from the unexpected low values of the inertial defects.

Key words: Rotational spectra; internal rotation; fluorine substitution; inertial defect 


\section{Introduction}

Fluorination has an important role in the pharmaceuticals, agrochemicals and materials [1-3]. The presence of fluorine has the potential to influence the biophysical properties of a molecule because of its size, electronegative and low polarizability [4,5]. At the molecular level, fluorination effect is often significant in changing the conformations, molecular structures and internal dynamics, which can be accurately described from the high resolution rotational spectroscopic investigations [6-8].

According to the rotational studies of fluoropyridine [9,10], fluorobenzene [11-13], fluorocyanobenzene [14] and fluorothiophenol [15], the fluorination at the ortho position of the aromatic ring has the largest geometry changes with an increase in the ring angle at that site by 3-4 $4^{\text {o }}$, and a reducing of the adjacent C-C bonds by 0.006-0.015 $\AA$. Besides the structural changes, recent studies on 2-fluorobenzylamine [16], 2-fluorophenylethanol [17] and fluorobenzyl alcohol derivatives [18-21] have shown that fluorination can also bring great alterations to conformational preferences.

Influence of the fluorination on the large amplitude motion is another interesting rotational feature caused by a considerable change in the steric effect and the electronic potential in the substituted region. For instance, toluene and $p$-fluorotoluene have $V_{6}$ barriers to the methyl internal rotation to be $57.87337 \mathrm{~J} / \mathrm{mol}[22,23]$ and $57.777 \mathrm{~J} / \mathrm{mol}$ [24] respectively, which suggest that fluorination at the para-position does not change barrier to methyl internal rotation substantially. However, the substitution in meta or para- position may reduce the symmetry and a $V_{3}$ potential barrier appears predominantly. Thus, in m-fluorotoluene the $V_{3}$ barrier found to be $189.535 \mathrm{~J} / \mathrm{mol}$ [25] whereas in o-fluorotoluene it is $2718.87 \mathrm{~J} / \mathrm{mol}$ [26]. 
Considerable attention has been devoted in pyridine and its derivatives as the wide range of application in coordination [27] and surface chemistry [28,29], whilst the information on the methyl derivatives is scarce. Rotational study of the 2-picoline found a $V_{3}$ barrier to be $2760 \mathrm{GHz}$ $\approx 1101 \mathrm{~J} / \mathrm{mol}[30]$. The structures and conformations of 3-picoline and 4-picoline were investigated by the vibrational spectra [31]. Concerning there is no rotational spectra about fluorination effect on the molecular structures and internal dynamics of picolines, herein, the rotational spectrum of 2-fluro-4-picoline (2F4P) have been investigated using pulsed jet Fourier transform microwave (FTMW) spectroscopic technique. The results are reported below.

\section{Experimental}

Rotational spectra was measured by using a pulsed jet FTMW [32] spectrometer with a coaxially oriented beam-resonator arrangement (COBRA) configuration [33] built at Chongqing University [34]. The spectrometer covers the 2-20 GHz frequency range and operated with the FTMW++ set of programs. Argon as the carrier gas at a stagnation pressure of $0.01 \mathrm{MPa}$ passed over the sample of $2 \mathrm{~F} 4 \mathrm{P}$ ( $\geq 98 \%$, commercial product from Adamas used without further purification) at $313 \mathrm{~K}$ and expanded through a solenoid valve (Parker-General Valve, Series 9, nozzle diameter $0.5 \mathrm{~mm})$ into the Fabry-Pérot cavity $\left(\sim 10^{-4} \mathrm{~Pa}\right)$. The spectra of the mono-substituted ${ }^{13} \mathrm{C}$ and ${ }^{15} \mathrm{~N}$ isotopologues were measured in natural abundance.

The spectral line positions were determined after Fourier transformation of the time domain signal with $8 \mathrm{k}$ data points, recorded at sampling intervals of $100 \mathrm{~ns}$. Due to the Doppler effect, each rotational transition is split into two component lines. The frequency is calculated from the arithmetic mean of the frequencies of the Doppler components. The accuracy of frequency measurements was better than $3 \mathrm{kHz}$ and lines separated by more than $6 \mathrm{kHz}$ were resolvable. 


\section{Results and Discussion}

\subsection{Theoretical calculations}

To aid the analysis of rotational spectra, theoretical calculations were first performed by using the program Gaussian 09 [35]. MP2/6-311++G(d,p) level of theory was initially chosen for geometry optimization, because of its proven performance in the prediction of molecular structures and electric dipole moments, including some aromatic molecules with methyl groups, such as $o$-methyl anisole [36], p-methyl anisole [37] and 2,5-dimethylthiophere [38]. The molecular structure of 2F4P is shown in Fig.1, where also the principal axes and atom numbering are given. The MP2/6-311++G(d,p) calculated spectroscopic parameters are summarized in the first column of Table 1 .

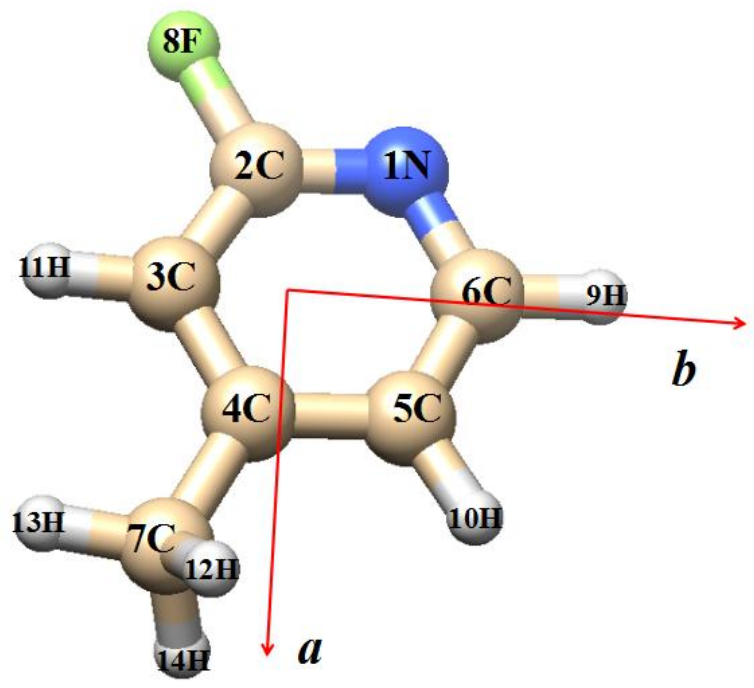

Fig. 1. Structure of 2F4P with principal axes and atom numbering.

The $V_{3}$ barrier to the internal rotation of methyl group has been calculated at the same level to be $43 \mathrm{~cm}^{-1}$. Therefore, splittings of rotational transitions contributable to the internal rotation of methyl top might be measured. The inertial defect $\Delta$ has been also calculated from theoretical rotational constants and reported in Table 1, which is of the common value contributed by three 
methyl hydrogens out of plane.

\section{Table 1}

Theoretical and experimental spectroscopic parameters of 2F4P.

\begin{tabular}{llll}
\hline & MP2 & B3LYP & Exp. \\
\hline$A / \mathrm{MHz}$ & 3850.38 & 3887.10 & $3920.950(2)^{\mathrm{a}}$ \\
$B / \mathrm{MHz}$ & 1775.37 & 1785.70 & $1788.5169(3)$ \\
$C / \mathrm{MHz}$ & 1224.40 & 1232.91 & $1231.2030(2)$ \\
$\chi_{\mathrm{aa}} / \mathrm{MHz}$ & -3.105 & -3.274 & $-3.080(3)$ \\
$\left(\chi_{\mathrm{bb}}-\chi_{\mathrm{cc}}\right) / \mathrm{MHz}$ & -2.328 & -2.472 & $-2.268(1)$ \\
$D_{\mathrm{J}} / \mathrm{kHz}$ & 0.063 & 0.065 & $0.051(2)$ \\
$D_{\mathrm{JK}} / \mathrm{kHz}$ & 0.01 & 0.170 & $0.76(1)$ \\
$D_{\mathrm{K}} / \mathrm{kHz}$ & 0.69 & 0.521 & $3.1(3)$ \\
$d_{\mathrm{1}} / \mathrm{kHz}$ & -0.023 & -0.022 & $-0.029(2)$ \\
$d_{2} / \mathrm{kHz}$ & -0.047 & -0.27 & $-0.013(2)$ \\
$\mu_{\mathrm{a}} / \mathrm{D}$ & 4.1 & 4.1 & Strong \\
$\mu_{\mathrm{b}} / \mathrm{D}$ & 0.4 & 0.4 & Weak \\
$\mu_{\mathrm{c}} / \mathrm{D}$ & 0.0 & 0.0 & None \\
$\Delta / \mathrm{u} \AA^{2}$ & -3.16 & -3.13 & -0.98 \\
$N^{b}$ & & & - \\
$\sigma^{c} / \mathrm{kHz}$ & & & 203 \\
\hline
\end{tabular}

${ }^{\mathrm{a}}$ Errors in parenthesis are $1 \sigma$ uncertainties expressed in units of the last digit.

${ }^{\mathrm{b}}$ Number of lines in the fit.

${ }^{\mathrm{c}}$ RMS error of the fit.

\subsection{Rotational spectra}

Following the theoretical predictions, the preliminary trial search was aimed at finding $\mu_{\mathrm{a}}-R$-branch transitions of $2 \mathrm{~F} 4 \mathrm{P}$, which were predicted to be the most intense ones. Based on the

${ }^{14} \mathrm{~N}(I=1)$ quadrupole hyperfine pattern, as shown in Fig. 2 for the $6_{0,6} \leftarrow 5_{0,5}$ transition for example, it was easy to assign $\mu_{\mathrm{a}}-R$-branch transitions with $J_{\text {lower }}$ from 3 to 7 and $K_{\mathrm{a}}$ up to 4 from which the rotational constants $A, B$ and $C$ were well determined. The measurement was then 
extended to 47 less intense $\mu_{\mathrm{b}}$-type transitions. No $\mu_{\mathrm{c}}$ type transition was observed, which is in coincidence with the fact of the zero value of the $\mu_{\mathrm{c}}$ dipole moment component.

In spite of a careful scan up and down about $2 \mathrm{GHz}$ with respect to the frequency of several observed rotational transitions, no transition belonging to the other sub-level $E$-state could be assigned with unambiguity. It seems that fluorination on the 2-site of the aromatic ring can dramatically impact the internal dynamics of 4-picoline.

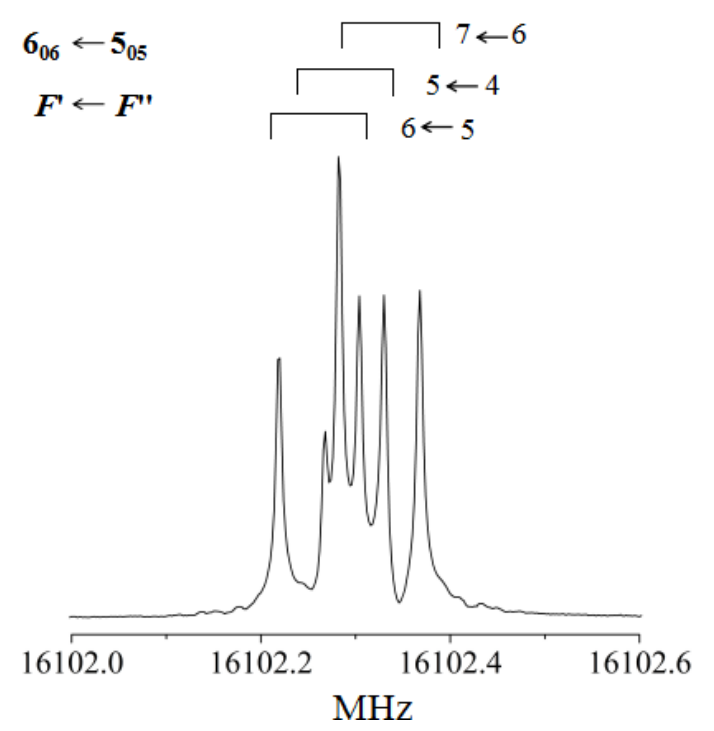

Fig. 2. Record $6_{06}-5_{05}$ rotational transition of $2 \mathrm{~F} 4 \mathrm{P}$ showing the ${ }^{14} \mathrm{~N}$ nuclear quadrupole hyperfine structure $\left(F^{\prime} \leftarrow F^{\prime \prime}\right)$. Each line appears as a doublet (indicated by square bracket) due to the instrumental Doppler effect.

The measured transition frequencies were fitted with Pickett's SPFIT program [39], according to the following Hamiltonian:

$H=H_{\mathrm{R}}+H_{\mathrm{CD}}+H_{\mathrm{Q}}$

where $H_{\mathrm{R}}$ represents the rigid rotational parts of the Hamiltonian. The centrifugal distortion contributions (analyzed by using the $S$ reduction and $I^{\mathrm{r}}$ representation) [40] are represented by 
$H_{\mathrm{CD}} . H_{\mathrm{Q}}$ is the operator associated with the ${ }^{14} \mathrm{~N}$ nuclear quadrupolar interaction. The obtained rotational, centrifugal distortion and quadrupole coupling constants are listed in the third column of Table 1.

After a first structural adjustment, it was possible to assign rotational spectra of all mono-substituted ${ }^{13} \mathrm{C}$ and ${ }^{15} \mathrm{~N}(I=1 / 2)$ isotopologues in natural abundance. All the corresponding spectroscopic parameters are summarized in Table 2. Since much smaller number of lines could be observed, the centrifugal distortion constants cannot be well-determined and are all fixed at the values obtained for the parent species.

Rotational transition frequencies measured for all 8 isotopologues are summarized in the Supplementary Materials.

\section{Table 2}

The experimental spectroscopic constants of all measured isotopologues of $2 \mathrm{~F} 4 \mathrm{P} .{ }^{\text {a }}$

\begin{tabular}{cccccccc}
\hline \multicolumn{1}{c}{${ }^{15} \mathrm{~N} 1$} & ${ }^{13} \mathrm{C} 2$ & ${ }^{13} \mathrm{C} 3$ & ${ }^{13} \mathrm{C} 4$ & ${ }^{13} \mathrm{C} 5$ & ${ }^{13} \mathrm{C} 6$ & ${ }^{13} \mathrm{C} 7$ \\
\hline$A / \mathrm{MHz}$ & $3889.800(6){ }^{\mathrm{b}}$ & $3918.801(3)$ & $3891.530(3)$ & $3919.063(3)$ & $3882.371(3)$ & $3832.570(3)$ & $3895.567(3)$ \\
$B / \mathrm{MHz}$ & $1779.1878(3)$ & $1781.1176(3)$ & $1788.5301(3)$ & $1778.2012(3)$ & $1779.6552(3)$ & $1788.5095(3)$ & $1745.8755(3)$ \\
$C / \mathrm{MHz}$ & $1223.7113(3)$ & $1227.4873(1)$ & $1228.3013(1)$ & $1226.1263(1)$ & $1223.1964(1)$ & $1222.3462(2)$ & $1208.4110(1)$ \\
$\chi_{\mathrm{aa}} / \mathrm{MHz}$ & - & $-3.05(5)$ & $-3.09(5)$ & $-3.05(5)$ & $-3.03(5)$ & $-3.08(5)$ & $-3.15(5)$ \\
$\left(\chi_{\mathrm{bb}-} \chi_{\mathrm{cc}}\right) / \mathrm{MHz}$ & - & $-2.260(8)$ & $-2.272(8)$ & $-2.256(8)$ & $-2.368(8)$ & $-2.260(8)$ & $-2.172(8)$ \\
$\Delta / \mathrm{uA} \AA^{2}$ & -0.986 & -0.987 & -0.988 & -0.987 & -0.986 & -0.984 & -0.984 \\
$N^{c}$ & 23 & 51 & 54 & 51 & 54 & 51 & 54 \\
$\sigma^{d} \mathrm{kHz}$ & 2.2 & 2.3 & 3.3 & 3.3 & 2.7 & 3.3 & 3.0 \\
\hline
\end{tabular}

\footnotetext{
${ }^{a}$ Centrifugal distortion constants have been fixed to those of normal species.

${ }^{\mathrm{b}}$ Errors in parenthesis are $1 \sigma$ uncertainties expressed in units of the last digit.

${ }^{c}$ Number of lines in the fit.

${ }^{\mathrm{d}}$ RMS error of the fit.
}

\subsection{Internal dynamics}

The experimental values of the inertial defects $\Delta$, for all seven isotopologues, were 
calculated from rotational constants and are summarized in Table 1 and 2. They are all much smaller in absolute values than that within the rigid approximation $\left(\Delta=-3.16 \mathrm{u} \AA^{2}\right)$ which can be interpreted by a low barrier to internal rotation of the $\mathrm{CH}_{3}$ group. The low-barrier to internal rotation of $\mathrm{CH}_{3}$ modifies the rotational constants of the $A$-state with respect to the "rigid" value and, consequently, the inertial defects of all isotopoloues. This can be explained qualitatively if taking into account the effective rotational constants of the ground state, $v=0, \sigma=0(\sigma=0, \pm 1$ for $A$ and $E$ species, respectively), as discussed in $\mathrm{CF}_{3} \mathrm{Cl}-\mathrm{CH}_{3} \mathrm{~F}$ [41], $\mathrm{CF}_{3} \mathrm{Cl}-\mathrm{CH}_{2} \mathrm{O}$ [42] and $\mathrm{CH}_{3} \mathrm{Cl}-\mathrm{H}_{2} \mathrm{O}$ [43], according to:

$$
\begin{aligned}
& A_{00}=A_{\mathrm{r}}+W_{00} F \rho_{\mathrm{a}}^{2} \\
& B_{00}=B_{\mathrm{r}}+W_{00} F \rho_{\mathrm{b}}^{2} \\
& C_{00}=C_{\mathrm{r}}+W_{00} F \rho_{\mathrm{c}}{ }^{2}
\end{aligned}
$$

in which $A_{\mathrm{r}}, B_{\mathrm{r}}$ and $C_{\mathrm{r}}$ are the rigid rotational constants, while $F$ is the "reduced" rotational constant of the methyl top. $W_{00}$ are the Herschbach's barrier dependent perturbation sums relative to the sublevels of the $A$-symmetry $(\sigma=0)$ species of the torsional ground state $(v=0)$. $\rho_{\mathrm{g}}=\lambda_{\mathrm{g}} I_{\alpha} / I_{\mathrm{g}}(g=a, b, c)$, where $I_{\alpha}$ is the moment of inertia of the methyl top, while $I_{\mathrm{g}}$ is the structural moments of inertia components of the molecule and $\lambda_{\mathrm{g}}$ is the direction cosines between the internal rotation axis $\alpha$ and principal axis $g(v=0)$. Values of the $W_{00}$ as a function of the reduced barrier $s$ are available [44]. The parameter $s$ is, in turn, related to the $V_{3}$ barrier according to $V_{3}=0.215 s F$.

As indicated in Fig.1, the $c$-axis is perpendicular to the internal rotation axis of the $\mathrm{CH}_{3}$ top. Therefore $\lambda_{\mathrm{c}}, \rho_{\mathrm{c}}$ and $F \rho_{\mathrm{c}}$ are zero, and the rotational constant $C$ is not affected by the internal rotations of $\mathrm{CH}_{3}$. In the contrast, the rotational constants $A$ is strongly affected by the barrier to 
the internal rotation of $\mathrm{CH}_{3}$ due to the almost co-linearity of the $a$-axis with the $\mathrm{C} 4 \mathrm{C} 7$ bond. As a consequence, experimental rotational constants $A$ and $B$ cannot be used directly for the structure fit. In order to know better the structure of $2 \mathrm{~F} 4 \mathrm{P}$, geometry optimizations were carried out at various levels of theory (see in Supplementary Materials). The predicted rotational constant $C$ calculated at the B3LYP/6-311++G(df,p) level (see in the second column of Table 1) matches best the experimental one, with the discrepancy of $0.2 \%$. B3LYP/6-311++G(df,p) geometry is then chosen, from which $F \rho_{\mathrm{a}}=76.126 \mathrm{MHz}$ and $F \rho_{\mathrm{b}}=4.311 \mathrm{MHz}$. By applying the differences between the model calculated and the experimental values of $A$ and $B$ to eq.(2), all seven isotopologues give $W_{00}=0.44$, which corresponds to a rather small internal rotational barrier $V_{3} \approx$ $16 \mathrm{~cm}^{-1}$, smaller than that expected from theoretical calculations. This very low barrier is responsible of larger splittings. In 2-butynoic acid, the barrier height is $1.00900(42) \mathrm{cm}^{-1}$ [45] while the splitting can reach a few hundred $\mathrm{MHz}$ even at low $J$ values.

\subsection{Molecular structure}
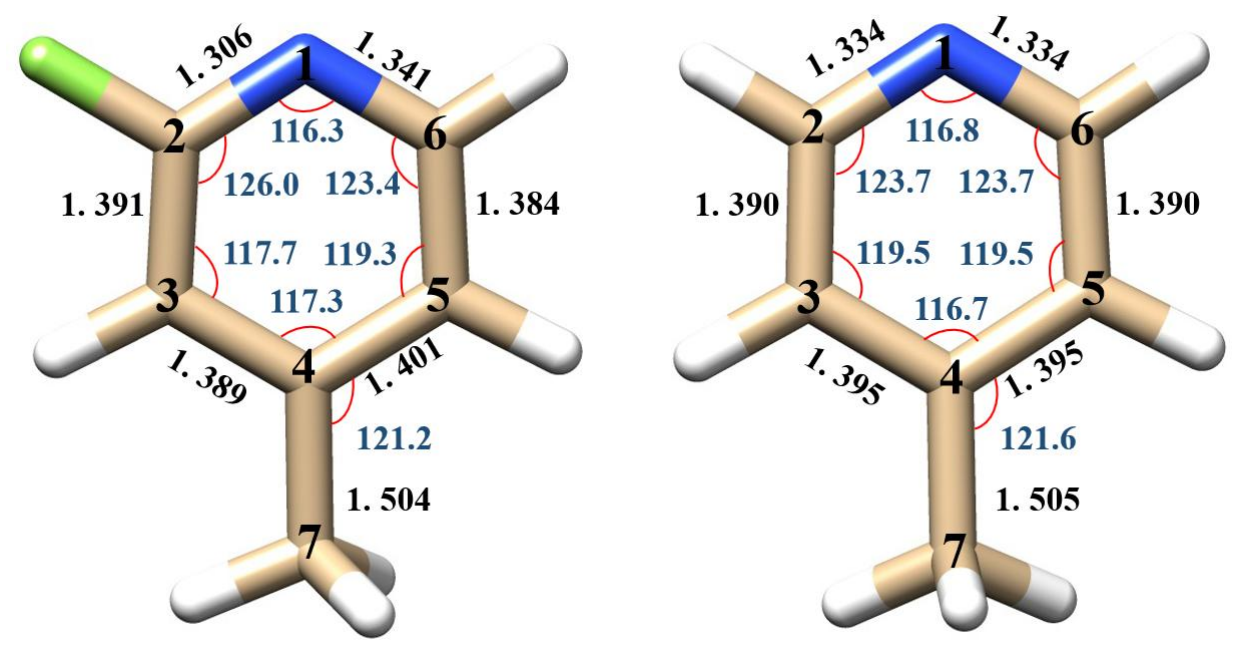

Fig. 3. The geometry of 2F4P and 4-picoline.

Full geometry of 2F4P is available calculated at B3LYP/6-311++G(df,p) level of theory. 
The geometry of 4-picoline is also calculated at the same level for comparison. As indicated in Fig. 3, the theoretical values show significant deviation from the nonsubstituted molecule. Upon the fluorination at the 2 -site of the aromatic ring, the N1-C2 bond is shortened by $0.028 \AA$ and the $\mathrm{N} 1 \mathrm{C} 2 \mathrm{C} 3$ angle increased $2.3^{\circ}$. This kind of variation, as discussed in 2-fluoropyridine and 3-fluoropyridine [9], is contributable to the electron withdrawing nature of fluorine. The valence angle centered at the fluorinated carbon atom increases $\sim 3^{\circ}$ with respect to pyridine.

To better reveal the alteration of electron distribution caused by fluorine substitution, molecular electrostatic surface potentials (MESP) of 4-picoline and 2F4P were performed at the B3LYP/6-311++g(df,p) level of theory, as shown in Fig. 4. The electron density shared between $\mathrm{N} 1$ and C2 shows a noticeable increase upon the fluorine substitution, while the other hydrogens become more acidic.

\section{$-2.4 \mathrm{e}-2$}
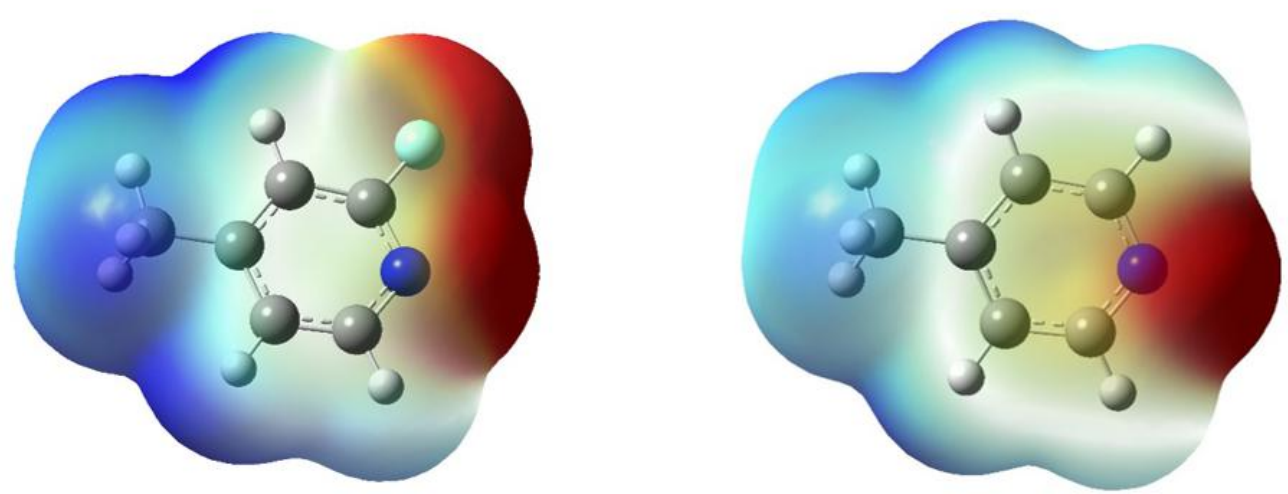

Fig. 4. The MESPs of 2F4P and 4-picoline.

\section{Conclusion}

The rotational spectrum of $2 \mathrm{~F} 4 \mathrm{P}$ have been investigated by using the pulsed jet Fourier transform microwave technique, which displays the features of the quadrupole coupling effect of 
the ${ }^{14} \mathrm{~N}$ nucleus with the near-free internal rotation of $\mathrm{CH}_{3}$ top. The $V_{3}$ barrier $\left(16 \mathrm{~cm}^{-1}\right)$ to the internal rotation of $\mathrm{CH}_{3}$ has been estimated from the unexpected low values of the inertial defects. It seems that fluorination at the 2-site of the aromatic ring alters not only the geometry but also the internal dynamics of 4-picoline.

\section{Acknowledgement}

We are grateful for support from the National Natural Science Foundation of China (Grant Nos. 21703021 and U1931104), Natural Science Foundation of Chongqing, China (Grant Nos. cstc2017jcyjAX0068 and cstc2018jcyjAX0050), Venture \& Innovation Support Program for Chongqing Overseas Returns (Grant No. cx2018064), Foundation of 100 Young Chongqing

University (Grant No. 0220001104428), and Fundamental Research Funds for the Central Universities (Grant No. 2018CDQYHG0009).

\section{References}

[1] F.M. Ismail, J. Fluo. Chem. $118 \quad$ (2002) 27-33. https://doi.org/10.1016/S0022-1139(02)00201-4

[2] P. Jeschke, ChemBioChem. 5 (2004) 570-589. https://doi.org/10.1002/cbic.200300833

[3] G. Lewandowski, E. Meissner; E. Milchert, J. Hazard. Mater. 136 (2006) 385-391. https://doi.org/10.1016/j.jhazmat.2006.04.017

[4] K.L. Kirk, Org. Process Res. Dev. 12 (2008) 305-321. https://doi.org/10.1021/op700134j

[5] C. Isanbor, D. O’Hagan, J. Fluo. Chem. 127 (2006) 303-319. https://doi.org/10.1016/j.jfluchem.2006.01.011

[6] K. Müller, C. Faeh, F. Diederich, Science. $317 \quad$ (2007) 1881-1886. 
https://doi.org/10.1126/science.1131943

[7] M. Cametti, B. Crousse, P. Metrangolo, R. Milani, G. Resnati, Chem. Soc. Rev. 41 (2012) 31-42. https://doi.org/10.1039/C1CS15084G

[8] R. Berger, G. Resnati, P. Metrangolo, E. Weberd, J. Hulliger, Chem. Soc. Rev. 40 (2011) 3496-3508. https://doi.org/ 10.1039/c0cs00221f

[9] C.W. van Dijk, M. Sun, J. van Wijngaarden, J. Phys. Chem. A. 116 (2012) 4082-4088. https://doi.org/10.1039/B406892K

[10] C.W. van Dijk, M. Sun, J. van Wijngaarden, J. Mol. Spectrosc. 280 (2012) 34-41. https://doi.org/10.1016/j.jms.2012.05.007

[11] Z. Kisiel, E. Białkowska-Jaworska, L. Pszczólkowski, J. Mol. Spectrosc. 232 (2005) 47-54. https://doi.org/10.1016/j.jms.2005.02.006

[12] L. Nygaard, I. Bojesen, T. Pedersen, J. Rastrup-Andersen, J. Mol. Struct. 2. (1968) 209-215. https://doi.org/10.1016/0022-2860(68)80003-1

[13] S. Doraiswamy, S.D. Sharma, J. Mol. Struct. 102 (1983) 81-92. https://doi.org/10.1016/0022-2860(83)80008-8

[14] M. Kamaee, M. Sun, H. Luong, J.v Wijngaarden, J. Phys. Chem. A. 119 (2015) 10279-10292. https://doi.org/10.1021/acs.jpca.5b07379

[15] W Sun, J.V. Wijngaarden, J. Mol. Struct. $1144 \quad$ (2017) 496-501. https://doi.org/10.1016/j.molstruc.2017.05.051

[16] C. Calabrese, A. Maris, L. Evangelisti, W. Caminati, S. Melandri, Chemphyschem. 14 (2013) 1943-1950. https://doi.org/10.1002/cphc.201300121

[17] R. Karaminkov, S. Chervenkov, H.J. Neusser, Phys. Chem. Chem. Phys. 11 (2009) 2249-2255. https://doi.org/10.1039/b817519e

[18] R.G. Bird, A.E. Nikolaev, D.W. Pratt, J. Phys. Chem. A 115 (2011),11369-11377. https://doi.org/10.1021/jp2051905

[19] L. Evangelisti, L.B. Favero, W. Caminati, J. Mol. Struct. 978 (2010), 279-281. https://doi.org/10.1016/j.molstruc.2010.02.022

[20] S. Tang, Z. Xia, A. Maris, W. Caminati, Chem. Phys. Lett. 498 (2010) 52-55. https://doi.org/10.1016/j.cplett.2010.08.066 
[21] L. Evangelisti, G. Feng, Q. Gou, W. Caminati, J. Mol. Struct. 1023 (2012) 15-17. https://doi.org/10.1016/j.molstruc.2012.01.004

[22] W.A. Kreiner, B.T. Tan, H.D. Rudolph, J. Mol. Spectrosc. 48 (1973) 86-99. https://doi.org/10.1016/0022-2852(73)90137-9

[23] V.V. Ilyushin, Z. Kisiel, L. Psczòlkowshi, H. Mäder, J.T. Hougen, J Mol. Spectrosc. 259 (2010) 26-38. https://doi.org/10.1016/j.jms.2009.10.005

[24] J. Rottstegge, H. Hartwig, H. Dreizler, J. Mol. Struct. 478 (1999) 37-47. https://doi.org/10.1016/S0022-2860(98)00656-5

[25] H.D. Rudolph, A. Trinkhaus, Z. Naturforsch. 23a (1968) 68-76. https://doi.org/10.1515/zna-1968-0112

[26] S. Jacobsen, U. Andersen, and H. Mäder, Struct. Chem. 14 (2003) 217-225. https://doi.org/10.1023/A:1022150801925

[27] J.P. Byrne, J.A. Kitchen, T. Gunnlaugsson, Chem. Soc. Rev. 43 (2014) 5302-5325. https://doi.org/10.1039/C4CS00120F

[28] I. Lokteva, N. Radychev, F. Witt, H. Borchert, J. Parisi, J. K. Olesiak, J. Phys. Chem. C. 114 (2010) 12784-12791. https://doi.org/10.1021/jp103300v

[29] J.F. Li, S.Y. Ding, Z.L. Yang, M.L. Bai, J.R. Anema, X. Wang, A. Wang, D.Y. Wu, S.M. Hou, T. Wandlowski, Z.Q. Tian, J. Am. Chem. Soc. 133 (2011) 15922-15935. https://doi.org/10.1021/ja2074533

[30] S. WÖRmke, K. Brendel, U. Andresen, MäDer, Mol. Phys. 102 (2004) 1625-1639. https://doi.org/10.1080/00268970410001725860

[31] I.L. TocoÂn, M.S. Woolley, J.C. Otero, J.I. Marcos, J. Mol. Struct. 470 (1998) 241-246. https://doi.org/10.1016/S0022-2860(98)00376-7

[32] T.J. Balle, W.H. Flygare, Rev. Sci. Instrum. $52 \quad$ (1981) 33-45. https://doi.org/10.1063/1.1136443

[33] J.U. Grabow, W. Stahl, H. Dreizler, Rev. Sci. Instrum. 67 (1996) 4072-4084. https://doi.org/10.1063/1.1147553

[34] J.U. Grabow, Q. Gou, G. Feng, 72nd International Symposium on Molecular Spectroscopy. (2017) TH03. 
[35] M.J. Frisch, G.W. Trucks, H.B. Schlegel, G.E. Scuseria, M.A. Robb, J.R. Cheeseman, G. Scalmani, V. Barone, B. Mennucci, G.A. Petersson, H. Nakatsuji, M. Caricato, X. Li, H.P. Hratchian, A.F. Izmaylov, J. Bloino, G. Zheng, J.L. Sonnenberg, M. Hada, M. Ehara, K. Toyota, R. Fukuda, J. Hasegawa, M. Ishida, T. Nakajima, Y. Honda, O. Kitao, H. Nakai, T. Vreven, J.A. Montgomery Jr., J.E. Peralta, F. Ogliaro, M. Bearpark, J.J. Heyd, E. Brothers, K.N. Kudin, V.N. Staroverov, R. Kobayashi, J. Normand, K. Raghavachari, A. Rendell, J.C. Burant, S.S. Iyengar, J. Tomasi, M. Cossi, N. Rega, J.M. Millam, M. Klene, J.E. Knox, J.B. Cross, V. Bakken, C. Adamo, J. Jaramillo, R. Gomperts, R.E. Stratmann, O. Yazyev, A.J. Austin, R. Cammi, C. Pomelli, J.W. Ochterski, R.L. Martin, K. Morokuma, V.G. Zakrzewski, G.A. Voth, P. Salvador, J.J. Dannenberg, S. Dapprich, A.D. Daniels, O. Farkas, J.B. Foresman, J.V. Ortiz, € J. Cioslowski, D.J. Fox, Gaussian 09 Revision D.01, Gaussian Inc, Wallingford, CT, 2009.

[36] L. Ferres, H. Mouhib, W. Stahl, H.V.L Nguyen, ChemPhysChem. 18 (2017) 1855-1859. https://doi.org/10.1002/cphc.201700276

[37] L. Ferres, W. Stahl, I. Kleiner, H.V.L Nguyen, J. Mol. Spectrosc. 343 (2018) 44-49. https://doi.org/10.1016/j.jms.2017.09.008

[38] V. Van, W. Stahl, H.V.L Nguyen, Phys. Chem. Chem. Phys. 17 (2015) 32111-32114. https://doi.org/10.1039/C5CP03513A

[39] H.M. Pickett, J. Mol. Spectrosc. $148 \quad$ (1991) 371-377. https://doi.org/10.1016/0022-2852(91)90393-O

[40] J.K.G. Watson, Elsevier, Amsterdam. 6 (1977) 1-89.

[41] Q. Gou, L. Spada, E.J. Cocinero, J Phys Chem Lett. 5 (2014) 1591-1595. https://doi.org/10.1021/jz500600w

[42] Q. Gou, G. Feng, L. Evangelisti, M. Vallejo-Lûpez, L. Spada, A. Lesarri, E.J. Cocinero, W. Caminati, Chem. Eur. J. 21 (2015) 4148-4152. https://doi.org/10.1002/chem.201406122

[43] Q. Gou, L. Spada, J.C. Lýpez, J.U. Grabow, W. Caminati, Chem-Asian J. 10 (2015) 1198-1203. https://doi.org/10.1002/asia.201500013

[44] D.R. Herschbach, J. Chem. Phys. 31 (1959) 91-108. https://doi.org/10.1063/1.1730343

[45] V. Ilyushin, R. Rizzato, L. Evangelisti, G. Feng, A. Maris, S. Melandri, W. Caminati. J. Mol. 
Spectrosc. 267 (2011) 186-190. https://doi.org/10.1016/j.jms.2011.03.028 